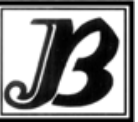

J. bio-sci. 17: 149-153, 2009

ISSN 1023-8654

http://www.banglajol.info/index.php/JBS/index

\title{
TOXICITY OF FOUR PLANT BASED PRODUCTS AGAINST THREE STORED PRODUCT PESTS
}

\author{
Debashish Talukder ${ }^{\star}$, L A Muslima Khanam \\ Bangladesh Council of Scientific and Industrial Research Laboratories, Rajshahi, Bangladesh
}

Abstract

Context: Plant essential oil play an important role in stored product pests protection. Emulsified oil can easily mix with water and also revealed the same insecticidal activity as essential oil of plants that could be used in store as well as in the field as an alternative synthetic insecticide.

Objectives: The objective of this study is to investigate the efficacy of emulsified petroleum ether extract of Acorus calamus L. rhizome alone and three other combination of plant materials against three stored product pests, viz. Callosobruchus chinensis L., Sitophilus oryzae (L.) and Tribolium castaneum (Herbst) in adult phase in laboratories condition.

Materials and method-Petroleum ether extract of different plant parts were emulsified. The emulsified products were $A$. calamus rhizome alone, $A$. calamus + Corchorus capsularis $L$. seed, $A$. calamus + Thevetia neriifolia Juss. seed and A. calamus + Zingiber cassumunar Roxb. rhizome. The residual film technique method was conducted to determine the $\mathrm{LC}_{50}$ value of above mentioned plant extract against three stored product pests.

Results: Noticeable mortality was noted for all species after 24 and 48 hours of the treatment with the emulsified products, although highest mortality of $C$. chinensis was observed with $A$. calamus alone after 24 hours but it varied at 48 hours where the $A$. calamus $+T$. neriifolia showed the most effective result. The $\mathrm{LC}_{50}$ values of $A$. calamus alone products were 13.30 and $6.59 \mu \mathrm{gcm}^{-1}$ and for $A$. calamus $+T$. neriifolia were 18.37 and $4.45 \mu^{-1} \mathrm{gcm}^{-1}$ against $C$. chinensis adults after 24 and 48 hours treatment respectively. A. calamus $+T$. neriifolia products showed the lowest $L C_{50}$ values $\left(43.27 \mu \mathrm{gcm}^{-1}\right)$ against Sitophilus oryzae at 24 hours treatment but it varied at 48 hours where A. calamus (L.) alone (13.72 $\mu \mathrm{gcm}^{-1}$ ) was found to be the most effective toxicant. A. calamus alone showed the lowest LC.50 values ( 166.78 and $123.55 \mu \mathrm{gcm}^{-1}$ ) against $T$. castaneum adults after 24 and 48 hours treatment.

Conclusion: Use of plants in controlling insect infestation would offer desirable solutions, especially in developing tropical countries, where plants are found in abundance everywhere, throughout the year.

Key words: Plant extract, Contact toxicity, Callosobruchus chinensis, Sitophilus oryzae, Tribolium castaneum.

\section{Introduction}

The natural products of plants come as an alternative ecologically more compatible in substitution to the synthetic insecticides (Rupp et al. 2006). The use of botanical pesticides to protect plants from pests is very promising because of several distinct advantages. Pesticidal plants are generally much safer than conventionally used synthetic pesticides. In addition, plant-based pesticides are renewable in nature and cheaper (Parugrug and Roxas 2008).

In Bangladesh Acorous calamus L., Zingiber cassumunar Roxb., Thevatia neriifolia Juss. and Corchorus capsularis Linn. grow abundantly. All these plant have more or less toxic materials. The toxicity of $A$. calamus rhizome oil due to the presence of (Z)- and (E)- asarones in rhizome oil (Park et al. 2002, Yao et al. 2008).

" Corresponding author 
Bhuiyan et al. (2008) identified 32 volatile constituent in the rhizome oil of $Z$. cassumunar. The main components in rhizome oil were triquinance1, 4-bis (methoxy) $(26.47 \%)$, Z- ocimene $(21.97 \%$ and terpinen4-ol (18.45\%). Nugroho et al. (1996) reported that two phenylbutanoid from rhizome of $Z$. cassumunar are active on chronic feeding bioassays and also active in the residue contact bioassay $\left(\mathrm{LC}_{50}\right.$ values of 0.5 and $3.6 \mu \mathrm{g} \mathrm{cm}^{-1}$ respectively) against the neonate larvae of Spodoptera litoralis. T. neriifolia (Yelow oleander) is large evergreen shrubs grow in gardens and roadside as ornamental plant. The thevetin (non-toxic) and thevotoxin (very toxic) were found to be present in seed kernel oil (Malek et al. 1996). He also reported that the toxicity of $T$. neriifolia is due to the presence of thevotoxin in seed oil. Its seed kernel provided $68.7 \%$ non drying oil.

Many workers mentioned the presence of glucoside, corchorin, corchsularin in the jute seed oil (Saha and Choudhury 1922, Karrer and Benerjee 1949, Khalique and Ahmed 1954, Khan et al. 2006). Khuda et al. (1963) describes the presence of strophanthidin $0.5 \%$ raffinose $4.5 \%$ and several glucosides one of which indentical with $\beta$-sitosterol-d-glucoside in the C. capsularis seed powder. Hossen et al. (2008) suggested that the extracted jute seed oil may use as insecticides due to its bitter test.

Most insecticide products contain a synergist whose role is to amplify the chemical activity of the other compounds in the formulation (Wanyika et al. 2009). It has also been suggested that vegetable oils act as synergists in bio-pesticide formulations (Tembo and Murfitt 1995). Toxicity studies on mixtures of different essential oils or their constituents against stored-product insects to demonstrate additive, synergistic or antagonistic effects are rare. Therefore, the following investigation was undertaken to evaluate the toxicity of different emulsified mixtures of plant essential oils, $A$. calamus, $C$. capsularis, $T$. neriifolia and $Z$. cassumunar against Callosobruchus chinensis (L.), Sitophilus oryzae L. and T. castaneum adults.

\section{Materials and Methods}

Stock culture of $C$. chinensis and $S$. oryzae were maintained in separate $1000 \mathrm{ml}$ beaker on sterilized cowpea and maize at $30 \pm 0.5^{\circ} \mathrm{C}$ in an incubator respectively. A standard mixture of whole wheat flour with powdered dry yeast in a ratio of 19:1 was used as food medium in case of $T$. castaneum reared.

Seeds of $C$. capsularis, $T$. neriifolia, rhizomes of $Z$. cassumunar and $A$. calamus were procured from the different area of Rajshahi, Bangladesh. All the parts were dried in a shade and finally dried in an oven at $40^{\circ} \mathrm{C}$. After drying these parts were crushed in a mortar and pestle and extracted by petroleum ether separately. Then extracted liquid was dried in a rotary evaporator and collected in a small reagent bottle, preserved at $4^{\circ} \mathrm{C}$ in a refrigerator. $5 \mathrm{ml} \mathrm{A}$. calamus extract were mixed with $5 \mathrm{ml}$ of other plant extract separately. Then $5 \mathrm{ml}$ of $2.6 \%$ Sodium hydroxide solution in distil water were added and was stirred vigorously for 15 minutes. In case of $A$. calamus, $10 \mathrm{ml}$ extract were mixed with $5 \mathrm{ml}$ Sodium hydroxide solution $(2.6 \%)$ in distilled water and stirred vigorously. Finally $15 \mathrm{ml}$ of emulsified product of $A$. calamus $+C$. capsularis $(\mathrm{Ac}+\mathrm{Cc}), A$. calamus $+T$. neriifolia $(\mathrm{Ac}+\mathrm{Tn})$, A. calamus $+Z$. cassumunar $(\mathrm{Ac}+\mathrm{Zc})$ and $A$. calamus $(\mathrm{Ac})$ alone were prepared.

To test insect mortality seven doses from four plants based emulsified product were prepared including control (only water). Ten days old of $T$. castaneum, S. oryzae, and C. chinensis were taken from the stock culture. Depending upon the susceptibility of the beetle's different experimental doses was taken which were selected after a preliminary test. The doses were $39.29,78.59,157.19,314.38 \mu \mathrm{g} \mathrm{cm}^{-1}$ for $S$. oryzae and C. chinensis; $157.19,314.38,417.55,628.72 \mu \mathrm{g} \mathrm{cm}^{-1}$ for $T$. castaneum. All the above doses were prepared by mixing the requisite amounts of the plant based products with $10 \mathrm{ml}$ water. The experiment was carried out adopting the method of residual film technique. For each test dose $1 \mathrm{ml}$ liquid was dropped on a Petri dish (9 
$\mathrm{cm}$ dia surface area $62.63 \mathrm{~cm}^{2}$ ) and then dried in an oven at $40^{\circ} \mathrm{C}$ for 4 hours. Ten adults insect from each of above group were then released on to the Petri dish and these were kept in an incubator at $30 \pm 1{ }^{\circ} \mathrm{C}, 70 \%$ relative humidity. The mortality was assessed after 24 and 48 hours of the treatment. The percentage of the mortality was corrected using Abbott's formula (Abbott 1925) and LC 50 values were determined by probit analysis (Busvine 1971).

\section{Results and Discussions}

Toxicity data of the products against adult of $C$. chinensis are shown in Table 1. All the product is toxic to the adult mortality and increased with the increasing exposure time. After 24 hours of treatment highest mortality was recorded with the $A c$ on $C$. chinensis adults. The $L C_{50}$ values of $A c$ were 13.30 and $6.59 \mathrm{\mu gcm}^{-1}$ at the respective time intervals. Whereas the $A c+T n$ revealed the lowest $L C 50$ values, $4.45 \mu \mathrm{gcm}^{-1}$, against $C$. chinensis adults at 48 hours after treatment. The $\mathrm{LC}_{50}$ values of $\mathrm{Ac}+\mathrm{Tn}$ were 18.37 and $4.45 \mu \mathrm{gcm}^{-1}, \mathrm{Ac}+\mathrm{Zc}$ were 74.26 and $6.67 \mathrm{\mu gcm}^{-1}$ and $A c+C c$ were 93.82 and $5.63 \mu_{\mathrm{gcm}}{ }^{-1}$ after 24 and 48 hours exposure time respectively. During 24 hour treatment their efficacy followed the order $A c>A c+T n>A c+Z c>A c+C c$ product. After 48 hours, their order of efficacy were $A c+T n>A c+C c>A c>A c+Z c$.

The data in the Table 1 provided evidence that all the plant based product used in the experiment were found to be effective in suppressing the $S$. oryzae adults. Ac+Tn exhibited the lowest $L_{50}$ value on $S$. oryzae adults after 24 hours where Ac was found to be the most effective toxicant against the beetle at 48 hours. The calculated $\mathrm{LC}_{50}$ values of $\mathrm{Ac}+\mathrm{Cc}, \mathrm{Ac}+\mathrm{Tn}, \mathrm{Ac}+\mathrm{Zc}$ and $\mathrm{Ac}$ were $77.63,43.27,84.61$ and $54.46 \mu \mathrm{g} \mathrm{cm}$ ${ }^{1}$ respectively against the $S$. oryzae adults after 24 hours. At 48 hours interval $A c+C c, A c+T n, A c+Z c$ and $A c$ were 23.32, 16.43, 32.87 and $13.72 \mu \mathrm{g} \mathrm{cm}^{-1}$ respectively against the same species. The order of the efficacy at 24 hours was $A c+T n>A c>A c+C c>A c+Z c$ products and at 48 hours the efficacy followed the order $A c>$ $A c+T n>A c+C c>A c+Z c$.

Toxic effects due to the application of four plant based products against $T$. castaneum adult are shown in Table 1. Results demonstrate that these entire plant based product were effective against the $T$. castaneum adult at all the duration. Ac exhibited lowest $\mathrm{LC}_{50}$ values at 24 and 48 hours treatment. The $\mathrm{LC}_{50}$ values of $\mathrm{Ac}$ was 113.44 and $7.82 \mu \mathrm{gcm}^{-1}, \mathrm{Ac}+\mathrm{Cc}$ was 403.66 and $313.95 \mu \mathrm{gcm}^{-1}, \mathrm{Ac}+\mathrm{Zc}$ was 547.08 and $452.51 \mu \mathrm{gcm}^{-}$ 1 and $A c+T n 887.68$ and $592.69 \mu \mathrm{gcm}^{-1}$ after 24 and 48 hours exposure time respectively. Their efficacy followed the order $A c>A c+C c>A c+Z c>A c+T n$ during 24 and 48 hour treatment.

Tembo and Murfitt (1995) reported that treatment with vegetable oils of groundnut, rape seed and sunflower combined with pirimiphos-methyl were effective than the pirimiphos methyl alone. Krishnarajah et al. (1985) observed that a 1:1 mixture of the essential oils of Cymbopogon nardus (L.) and Vitex negundo L. was more toxic than the individual oils against Sitotroga cerealella (Olivier). Kim et al. (2003) revealed the significant insecticidal activity of Cinnamonum cassia bark, oil, horse radish (Cocholeria aroracia) oil and mustard oil (Brassica juncea) with in 1 day after treatment against adults of $S$. oryzae and $C$. chinensis using direct contact application methods. Result of the present study is in agreement with the results of Park et al. (2002) who reported that essential oil of $A$. calamus oil was toxic to $S$. oryzae and $C$. chinensis adults when applied tropically. In the filter paper diffusion test ethanol extract of $A$. calamus caused $95.56 \%$ and $17.78 \%$ mortality to $S$. zamias at $314.54 \mu \mathrm{gcm}^{-1}$ and $78.63 \mathrm{\mu gcm}^{-1}$ respectively after 4 days treatment (Yao et al. 2008).Our results are in conformity with the result of Mahfuz and Khanam (2007), who reported that methanol extracts of $C$. capsularis showed tremendous toxicity against $T$. confusum adults. The present results supported the finding of Khanam et al. (2006), who reported that petroleum ether extract of $Z$. cassumunar rhizome, Thevetia neriifolia leaf and Thevetia neriifolia root caused highest mortality than those of other solvent extract against S. oryzae. 
Table 1. The toxicity of four plant based product against Callosobruchus chinensis, Sitophilus oryzae and T. castaneum adults.

\begin{tabular}{|c|c|c|c|c|}
\hline Test insect & $\begin{array}{c}\text { Hours after } \\
\text { treatment }\end{array}$ & $\begin{array}{c}\text { Plant } \\
\text { materials }\end{array}$ & $\begin{array}{c}\mathrm{LD}_{50} \text { (Fiducial limits) } \\
\left(\mu \mathrm{g} \mathrm{cm}^{-1}\right)\end{array}$ & $\begin{array}{l}\text { Regression equation } \\
\qquad\left(\chi^{2} \text { at } 2 \mathrm{df}\right)\end{array}$ \\
\hline \multirow{8}{*}{ C. chinensis } & \multirow{4}{*}{24} & $A$ & $93.82(66.15-133.09)$ & $Y=2.31+1.37 X(0.86)$ \\
\hline & & B & $18.37(4.09-82.47)$ & $Y=4.01+0.781 X(1.04)$ \\
\hline & & C & $74.26(50.26$ - 109.74) & $Y=2.53+1.32 X(1.34)$ \\
\hline & & D & $13.30(3.99-44.33)$ & $Y=3.55+1.29 X(0.47)$ \\
\hline & \multirow{4}{*}{48} & $A$ & $5.63(0.59-53.66)$ & $Y=4.15+1.12 X(0.09)$ \\
\hline & & B & $4.45(0.33-60.15)$ & $Y=4.29+1.08 X(0.12)$ \\
\hline & & C & $6.67(0.49-90.07)$ & $Y=4.40+0.726 X(0.61)$ \\
\hline & & D & $6.59(0.91-47.91)$ & $Y=3.95+1.28 X(0.39)$ \\
\hline \multirow{8}{*}{ S. oryzae } & \multirow{4}{*}{24} & $A$ & 77.63 (52.89-113.98) & $Y=1.40+1.90 X(0.44)$ \\
\hline & & B & 43.27 (23.67-79.09) & $Y=2.22+1.69 \times(0.27)$ \\
\hline & & C & $84.61(61.98-115.50)$ & $Y=0.485+2.34 X(0.17)$ \\
\hline & & D & $54.46(32.60-90.97)$ & $Y=2.03+1.71 X(0.04)$ \\
\hline & \multirow{4}{*}{48 hours } & $A$ & $23.32(7.62-71.31)$ & $Y=3.11+1.38 X(0.22)$ \\
\hline & & B & $16.43(3.45-78.10)$ & $Y=3.48+1.25 X(0.03)$ \\
\hline & & C & 32.87 (16.03-67.39) & $Y=2.34+1.75 X(0.10)$ \\
\hline & & D & $13.72(2.41-78.05)$ & $Y=3.60+1.23 X(0.22)$ \\
\hline \multirow{8}{*}{ T. castaneum } & \multirow{4}{*}{ 24hours } & A & $403.66(331.55$ - 491.46) & $Y=-3.48+3.25 X(1.29)$ \\
\hline & & B & $887.68(599.99-1313.29)$ & $Y=-3.42+2.85 X(3.19)$ \\
\hline & & C & $547.08(477.38-626.97)$ & $Y=-8.98+5.11 X(1.09)$ \\
\hline & & D & $166.78(102.07-272.51)$ & $Y=0.065+2.22 X(0.19)$ \\
\hline & \multirow{4}{*}{48 hours } & $A$ & $313.95(265.02-371.91)$ & $Y=-6.74+4.70 X(1.06)$ \\
\hline & & B & 592.69 (489.39 - 717.78) & $Y=-5.08+3.63 X(3.58)$ \\
\hline & & C & $452.51(380.30-538.42)$ & $Y=-6.14+4.19 X(1.19)$ \\
\hline & & D & $123.55(64.99-234.83)$ & $Y=0.365+2.21 X(0.97)$ \\
\hline
\end{tabular}

$\mathrm{A}=\mathrm{A}$. calamus $+\mathrm{C}$. capsularis $; \mathrm{B}=\mathrm{A}$. calamus $+T$. neriifolia; $\mathrm{C}=\mathrm{A}$. calamus $+\mathrm{Z}$. cassumunar $\mathrm{D}=\mathrm{A}$. calamus

\section{Acknowledgement}

The authors would like to express their sincere thanks to the Director, BCSIR Labs., Rajshahi for providing necessary laboratory facilities.

\section{References}

Abbott WS. 1925. A method of computing the effectiveness of an insecticide. J Econ Entomol 18, 265-267.

Bhuiyan MNI, Chowdhury JU, Begum J. 2008. Volatile constituents of essential oils isolated from leaf and rhizome of Zingiber cassumunar Roxb. Bangladesh J Pharmacol 3, 69-73. doi:10.3329/bjp.v3i2.844

Busvine JR . 1971. A Critical Review of the Techniques for Testing Insecticides. Commonwealth Agricultural Bureau, London. 345 pp.

Hossen M, Ali MS, Begum M, Khatton A, Halim A. 2008. Study on high yield of quality jute seed production for diversified uses.J Innov Dev strategy 2(3), 71-73

Karrer P, Banerjee P. 1949. Corchortoxin, a cardiac agent from Jute seeds. Helv Chim Acta 32, 2385-2392. doi:10.1002/hlca.19490320722 
Khalique MA, Ahmed M. 1954. Corchsularin, A new bitter from jute seeds I. Its isolation and constitution of corchsularose. J Org Chem 19, 1523-1528. doi:10.1021/j001374a017

Khan MSY, Bano S, Javed K, Mueed MA. 2006. A comprehensive review on the chemistry and pharmacology of Corchorus species-A source of cardiac glycosides, triterpenoids, inonnes, flavonoids, coumarins, steroids and some other compounds. J Sci Ind Res 65, 283-298

Khanam LAM, Talukder D, Dey KC. 2006. Bioactivity of some plant extracts against the rice weevil, Sitophilus oryzae. J Asiatic Soc Bangladesh (Sci) 32(2), 219-226

Khuda, Qudrat-I-, Khalique MA, Das DC. 1963. Examination of the constituents of jute seeds. Part-1. Isolation of jute seed oil, strophanthidin and Raffinose. Pak J Sci Ind Res 6(3), 158-160

Kim Soon-II, Roh JY, Kim DH, Lee HS, Ahn YJ. 2003. Insecticidal activities of aromatic plant extracts and essential oils against Sitophilus oryzae and Callosobruchus chinensis. J Stored Prod Res 39(3), 293-303. doi:10.1016/S0022474X(02)00017-6

Mahfuz I, Khanam LAM. 2007. Toxicity of some indigenous plant extracts against Tribolium confusum Duval. J bio sci 15, 133-138

Malek MA, Parveen B, Talukder D. 1996. Insecticidal Properties of four Indigenous plant extracts against adults of CR-1 strain of Tribolium castaneum Herbst. Bangladesh J Entomol 6(1\&2), 7-11

Nugroho BW, Schwarz B, Wray V, Proksch P. 1996. Insectididal constituents from rhizomes of Zingiber cassumunar and Kaempferia rotunda. Phytochem 41(1), 129-132. doi:10.1016/0031-9422(95)00454-8

Park C, Kim Soon-II, Ahn YJ. 2002. Insecticidal activity of asarones identified in Acorus gramineus rhizome against three coleopteran stored-product insects. J Stored Pro. Res 39(3), 333-342

Parugrug ML, Roxas AC. 2008. Insecticidal action of five plants against maize weevil, Sitophilus zeamais Motsch. (Coleoptera: Curculionidae). KMITL Sci Tech J 8(1), 24-38

Rupp MM , Cruz MES, Collella JCT, Junior SP, Souza Schwan-Estrada KRF, Cruz MJS, Fiori-Jutida AC. 2006. Evaluation of toxic effect of plant extracts on adults of Sitophilus oryzae L.1763 (Col., curculionidae). Proceedings of the 9th International Working Conference on Stored-Product Protection. Campinas, Brazil.

Saha H, Choudhuri KN. 1922. Capsularin, a glucoside from Jute leaf. J Chem Soc 121, 1044-1046

Tembo E, Murfitt, RFA. 1995. Effect of combining vegetable oil with pirimiphos-methyl for protection of stored wheat against Sitophilus granarius (L.). J Stored Prod Res 31(4), 355. doi:10.1016/0022-474X(96)81396-8

Wanyika HN, Kareru PG, Keriko JM, Gachangja AN, Kenji GM, Mukiira NJ. 2009. Contact toxicity of some fixed plant oils and stabilized natural pyrethrum extracts against adult maize weevils (Sitophilus zeamais Motschulsky). Afr J Pharm Pharma 3(2), 66-69

Yao Y, Cai W, Yang C, Xue D, Huang Y. 2008. Isolation and characterization of insecticidal activity of (Z)- asarone from Acorus calamus L. Insect Sci 15(3), 229-236. doi:10.1111/j.1744-7917.2008.00205.x 